\title{
An Intelligent Approach for Optimizing Supply Chain Operations
}

\author{
H. C. W. Lau, L. Zhao, and Dilupa Nakandala
}

\begin{abstract}
This paper aims to provide a model of supply chain management covering the principles of fuzzy logic for assessing performance of suppliers based on several pre-determined benchmarking metrics. Most important of all, it paves the way to extend this approach to tackle the issue of trans-shipment optimization where the stochastic nature of customer demand and supplier lead-time is taken into account.
\end{abstract}

Index Terms-Fuzzy logic, logistic management,
trans-shipment cost.

\section{INTRODUCTION}

Companies are striving to gain an appropriate percentage of the market share in today's competitive industrial environment, as they understand that the key of success in the competitive market is to generate substantial profit by operating the company in the lowest possible costs. Logistic costs is one of the largest part of the total costs which is difficult to identify it, and many organizations are surprised by their scale and start to look for savings from logistic costs [1]. Deloitte and Touche (1999) indicated that 98 percent of respondents agreed that logistics and supply chain management is either "critical" or "very important" to their company. Moreover, reducing operating costs has become the initial incentive for companies to examine their logistics and supply chain management strategies [2]. More and more companies are forming close relationships with their suppliers through strategic alliance and integration to ensure best quality of the sources and lower costs. Strategic alliance and integration with suppliers are considered as a win-win situation for the joint parties and can bring mutual benefits and open relationships wherein the needs of both parties are satisfied [3].

This paper aims to discuss the framework of supply chain management, embracing the principle of fuzzy logic to analyze and monitor the performance of suppliers based on the criteria of product quality and delivery time. By indicating the possible issues with the relevant suppliers prior to final confirmation, the proposed system is used to recommend the purchasing quantity to be placed in the next purchase order.

\section{RELATED STUDiES}

Strategic supply plan is developed to form a successful

Manuscript received November 10, 2013; revised January 15, 2014.

The authors are with the School of Business, University of Western Sydney, Locked Bag 1797, Penrith, New South Wales 2751, Australia (e-mail: H.Lau@uws.edu.au, zhaoli.xjtu@gmail.com, D.Nakandala@uws.edu.au). strategic supplier alliance and integration, and it acts as the road map of a company's supply chain management strategy [4]. The strategic supply plan defines the supply base and sets up a list of world-class suppliers for the relevant items. Plans and guidelines for selecting suppliers and setting up strategic partnership and alliance with them are also included. Furthermore, plans are developed to manage and maintain relationships with suppliers to ensure a long term relationship [3]. How to sustain and leverage the supplier relationship is the most difficult part of the supply chain management plan which requires a real-time monitoring system on product quality, delivery time and cost [5]. Business strategies, such as total quality management, just-in-time manufacturing, efficient customer response, vendor-managed inventory, and business process re-engineering, are adopted in 1990s to improve the productivity and ensure customer satisfaction, and meet the global demands [6].

Supply chain management is a critical company function, which strategically considers the objective of gaining competitive advantage for the company from the effective supply chain management. Early in the 1990s, supply management policy has been increasingly recognized as a strategic means tantamount to the firm's other operational strategies [7], [8]. Zairi (1999) suggested that supply chain management consists of value-adding and optimization in the use of all resources, materials, people, technology and information for the benefit of the end customer [9]. Nisel (2001) also emphasized the importance of satisfying consumer needs which is the ultimate goal for success in business [10]. However, even for best-practice approaches and systems for supply chain management, deficiency still exist which hinders the guidance to the executive personnel in efficient supply chain management [11].

Ballou (1999) suggested that, to be successful, the emphasis should be on logistic control as it helps ensure that the goals of the logistics plans should be achievable [12]. Besides the importance of deploying a successful logistic control, building and maintaining good business relationships is also critical with the adoption of technologies and algorithms [13]. For example, deploying a methodology that can provide enough flexibility to describe relationship which is difficult to be measured with crisp or quantitative values helps maintain good business relationships. Fuzzy logic method is frequently adopted to deal with "gray" areas that often happen in real life situations [14], [15], and it is also useful in dealing with supply chain issues. For example, a company is evaluating a group of suppliers by the number of production lines each supplier owns. The company groups the suppliers into two classes: preferable partners and non-preferable partners. Suppliers with less than 10 production lines are considered as non-preferable partners 
and suppliers with more than 10 production lines as preferable partners. According to this rule, suppliers with 9 production lines are classified as non-preferable partners even though they are just one production line less than suppliers with 10 production lines. However, the suppliers with 9 production lines may still be able to provide good quality products with good top management team and skillful workers. This example provides an example of dealing with inherently fuzzy concepts in a crisp way which cannot reflect the real situation [14]-[17].

A fuzzy logic approach is proposed in this study to help maintain product quality, timeliness and cost effectiveness to meet the global demands. The model developed in this study evaluates the defection rate and delivery time, thereby providing an assessment approach to deal with the unknown factors of cost measurement, and suggesting an adjustment on next time order quantity from a specific supplier. The proposed infrastructure adopts the fuzzy logic approach to monitor the supply chain with a continuous iterative process that learns from previous results.

\section{THE PROPOSED FRAMEWORK}

Setting up effective supply chain partnership helps guarantee product quality and supply chain effectiveness which in turn creates a win-win situation for all the supply chain members. Several steps have to be set up to develop an effective supply chain partnership (see Fig. 1). A mathematical approach with fuzzy logic principles is recommended in this study to monitor the supply chain performance by evaluating the planned and actual performances, such as ongoing delivery time and product quality, and making adjustment in order quantity based on the actual performance. The proposed methodology is to complement the authors' previous research publications on supply chain management with the multi-agent technologies [18], genetic algorithm [19], distributed object technology [20], and neural network [21].

\section{A. Cost Function for Supply Chain Management}

The following function is developed to monitor the relationship and performance of the supply chain partners based on costs and risks [22] (Eilon et al., 1971).

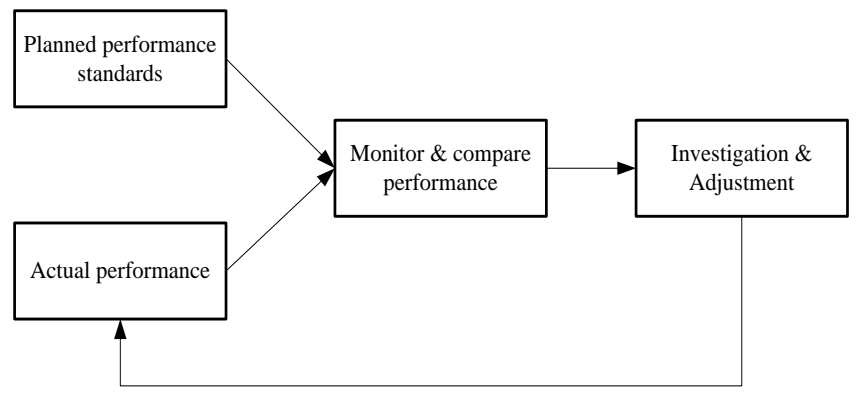

Fig. 1. The proposed supplier performance monitoring system.

Total Cost $=$ Variable Cost + Fixed Cost + Unpredicted Cost

The error measurement of Eilon (1971)'s formula is added in calculating the total cost as the unpredicted cost. Equation (1) expresses the function in mathematical expression:

$$
\text { Total Cost Function }=\sum_{x, y}\left(C_{x y} Q_{x y}\right)+\sum_{x} F_{x} S_{x}+\text { error }
$$

where

$$
\begin{aligned}
\text { Variable Cost Function } & =\sum_{x, y}\left(C_{x y} Q_{x y}\right) \\
\text { Fixed Cost Function } & =\sum_{x} F_{x} S_{x}
\end{aligned}
$$

Unpredicted cost $=$ error

Subject to:

$$
\sum_{x} Q_{x}=\sum_{y} W_{y}
$$

where

$x=1,2, \ldots, n$ where $n$ is an integer; represents different suppliers;

$y=1,2, \ldots, m$ where $\mathrm{m}$ is an integer; represents different production plans;

$C_{x y}=$ Cost of ordering one unit from supplier $x$ to production plan y;

$Q_{x y}=$ Ordering quantity from supplier $x$ to production plan y;

$Q_{x}=$ Number of units ordering from supplier $x$;

$W_{y}=$ Number of units the production plan $y$ needs, which depend on the customer demand;

$F_{x}=$ Fixed costs such as contract cost, quota limitation for ordering from supplier $x$;

$S_{x}=$ Strategic variable from supplier $x$ ordering or not ordering. If ordering from supplier $x, S_{x}=1$, otherwise, $S_{x}$ $=0$

This model is given for easy understanding. The total and variable costs are known and easily calculated with simple accounting system. Therefore, the focus of this study is to find the unpredicted costs. The unpredicted costs caused by unknown factors are measured based on past transaction data on the suppliers in terms of delivery time and product quality. The unknown factors are hard to measure using traditional methods such as quantitative method. Thus, the fuzzy logic approach is adopted in this study to measure the reliability of the suppliers. More specifically, historical data on delivery time and product quality is used to evaluate the unknown factors and adjust the ordering from relevant suppliers. In our proposed system, a warning is fired if the "safety level" is overshot, and the warning suggests an increase or decrease of the next purchase order based on the supplier's delivery time and product quality.

\section{B. Adoption of Fuzzy Logic}

Delivery time is measured and evaluated based on the number of days earlier or later than the promised day of delivery. Early delivery is not acceptable as it requires space for inventory storage and extra works to handle placement of inventory which in turn increase the costs. Also, early delivery may affect the company's financial status as the payment will be due earlier than expected. On the other hand, late delivery is obviously harmful to the company as it would delay the whole production process and cause extra costs for the delay. Late delivery could also affect the downstream 
supply chain partners in the supply chain and prolong the production cycle, and fail to provide products to customer in time.

TABLE I: DELIVERY TIME MEASUREMENT

\begin{tabular}{ll}
\hline \hline Delivery Time & Standard \\
\hline More than 4 days early $(>4)$ & Fail \\
\hline 4 days early (4) & Acceptable \\
\hline 3 days early (3) & Acceptable \\
\hline 2 days early (2) & Acceptable \\
\hline 1 day early (1) & Fine \\
\hline Promised delivery day & Fine \\
\hline 1 day late $(-1)$ & Acceptable \\
\hline 2 days late $(-2)$ & Acceptable \\
\hline More than 2 days late $(>-2)$ & Fail \\
\hline \hline
\end{tabular}

Table I describes the delivery time measurement, while Fig. 2 shows the fuzzy sets of delivery time that represents the standard in degree of membership. If delivery time is more than 4 days earlier than expected, it is unacceptable and the degree of membership is 0 . For deliveries 2 to 4 days earlier than expected, it is acceptable and the degree of membership is a linear relationship with the delivery time. For delivery 1 day early and on the promised day, the degree of membership is 1 . However, if the delivery is 1 to 2 days late, it is also acceptable with a linear membership function. For deliveries more than 2 days later than expected, it is not acceptable.

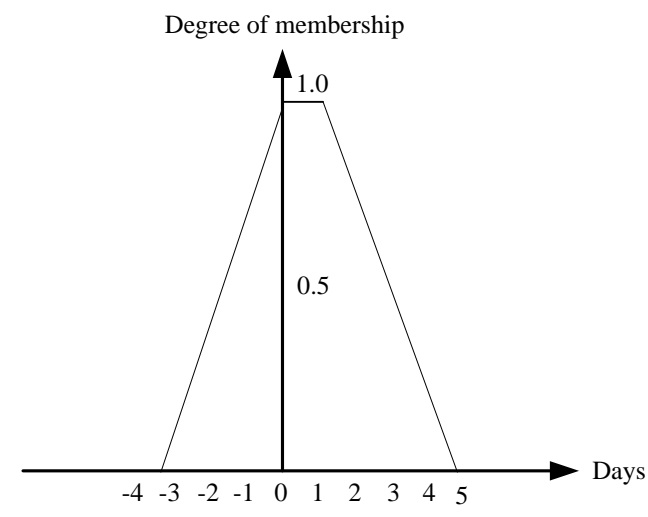

Fig. 2. Fuzzy set of delivery days.

Product quality is evaluated based on number of rejected goods and defect rate of products (Table II). Percentage of defection is calculated as follows:

Quality value $=(($ number of rejected goods + defect goods)/ total quantity of the ordered lot) $\times 100 \%$.

TABLE II: QUALITY MEASUREMENTS

\begin{tabular}{ll}
\hline \hline Quality Value (defect percentage) & Standard \\
\hline$=<1 \%$ & Fine \\
\hline $2 \%$ & Acceptable \\
\hline $3 \%$ & Acceptable \\
\hline $4 \%$ & Acceptable \\
\hline $5 \%$ & Acceptable \\
\hline$>5 \%$ & Fail \\
\hline \hline
\end{tabular}

Table III shows the rule blocks of change of next order quantity described in fuzzy terms, such as substantial decrease (SD), Considerable decrease (CD), some decrease (SMD), little decrease (LD) and no change (NC). For example, if supplier A has failed the delivery time and product quality, the system will recommend substantial decrease for the next order. If the delivery time is failed and the product quality is fine, then the system will recommend some decrease in next order's quantity. This system is fair as the guideline is based on the previous data and the experts' knowledge in this area. Moreover, this system is flexible as the rules can be adjusted according to different situations and needs, such as different suppliers and different products may have different delivery time and quality demand.

TABLE III: CHANGE OF NEXT ORDER QUANTITY

\begin{tabular}{lll}
\hline \hline Delivery Time & Quality & Quantity \\
\hline Fail & Fail & Substantial Decrease (SD) \\
\hline Fail & Acceptable & Considerable Decrease (CD) \\
\hline Fail & Fine & Some Decrease (SMD) \\
\hline Acceptable & Fail & Considerable Decrease (CD) \\
\hline Acceptable & Acceptable & Some Decrease (SMD) \\
\hline Acceptable & Fine & Little Decrease (LD) \\
\hline Fine & Fail & Some Decrease (SMD) \\
\hline Fine & Acceptable & Little Decrease (LD) \\
\hline Fine & Fine & No Change (NC) \\
\hline \hline
\end{tabular}

A weighted average of the delivery time and quality will be calculated with the most recent records in order to generate a fair performance assessment. As described in Table IV and Table V, the latest record (Record 1) has the heaviest weighting (40\%), followed by $30 \%$ for Record $2,20 \%$ for Record 3 and the fourth record is counted only $10 \%$. On the other hand, if there are only three past records, an adjustment of weightings is made to make up a total of $100 \%$ (in this case, $50 \%, 30 \%, 20 \%)$. A more fair result is generated by calculating the weighted average as the most recent record provides the latest information about the supplier performance.

TABLE IV: WEIGHTED AVERAGE FOR SUPPLIER DELIVERY TIME ASSESSMENT

\begin{tabular}{|c|c|}
\hline $\begin{array}{l}\text { Records } \\
\text { Completed } \\
\end{array}$ & Weighted Method \\
\hline 1 & Delivery Time of Record1 x $100 \%$ \\
\hline 2 & $\begin{array}{l}\text { Delivery Time of Record } 1 \times 75 \%+\text { Delivery Time of } \\
\text { Record } 2 \times 25 \%\end{array}$ \\
\hline 3 & $\begin{array}{l}\text { Delivery Time of Record } 1 \text { x } 50 \%+\text { Delivery Time of } \\
\text { Record } 2 \text { x } 30 \%+ \\
\text { Delivery Time of Record } 3 \text { x } 20 \%\end{array}$ \\
\hline 4 & $\begin{array}{l}\text { Delivery Time of Record } 1 \text { x } 40 \%+\text { Delivery Time of } \\
\text { Record } 2 \times 30 \%+ \\
\text { Delivery Time of Record } 3 \times 20 \%+\text { Delivery Time of } \\
\text { Record } 4 \text { x } 10 \%\end{array}$ \\
\hline
\end{tabular}

TABLE V: WEIGHTED AVERAGE FOR SUPPLIER DEFECT RATE ASSESSMENT

\begin{tabular}{|c|c|}
\hline $\begin{array}{l}\text { Records } \\
\text { Completed }\end{array}$ & Weighting Method \\
\hline 1 & Defect Percentage of Record $1 \times 100 \%$ \\
\hline 2 & $\begin{array}{l}\text { Defect Percentage of Record } 1 \times 75 \%+\text { Defect } \\
\text { Percentage of Record } 2 \times 25 \%\end{array}$ \\
\hline 3 & $\begin{array}{l}\text { Defect Percentage of Record } 1 \times 50 \%+\text { Defect } \\
\text { Percentage of Record } 2 \times 30 \%+ \\
\text { Defect Percentage of Record } 3 \times 20 \%\end{array}$ \\
\hline 4 & $\begin{array}{l}\text { Defect Percentage of Record } 1 \times 40 \%+\text { Defect } \\
\text { Percentage of Record } 2 \times 30 \%+ \\
\text { Defect Percentage of Record } 3 \times 20 \%+\text { Defect } \\
\text { Percentage of Record } 4 \times 10 \%\end{array}$ \\
\hline
\end{tabular}




\section{Defuzzification}

In order to convert the fuzzy values to crisp value, defuzzfication is performed. Adopting the most commonly used methods, such as center of area, the crisp value is got to be used in the quantity control for the next order.

\section{CASE STUdY}

A case study in a toy manufacturing company is provided in this section to provide a clear view on the approach and methodology. A set of data is collected from the corporate database of the Toy Manufacturing Company for analysis purpose. Only the last four records of one of the supplier partner (called Mayon Plastic Supply Co.) are used for simplicity to demonstrate the use of the fuzzy logic approach (see Table VI A), Table VI B). The weighted average of the most recent four records is taken to forecast the defect rate and delivery time of next order, which helps make adjustment in the next order quantity from this supplier.

TABLE Vi A): Most Recent Products Records of Mayon Plastic SUPPLY CO.

\begin{tabular}{lll}
\hline \hline No. & Defect Rate (\%) & Delivery Time (Days) \\
\hline 1 & $5 \%$ & -2 \\
\hline 2 & $3 \%$ & -2 \\
\hline 3 & $2 \%$ & -1 \\
\hline 4 & $0 \%$ & -2 \\
\hline \hline
\end{tabular}

TABLE VII B): THE PERFormance of MAyon Plastic SuPPly Co ACCORDING TO FOUR LATEST RECORDS

\begin{tabular}{lllll}
\hline \hline No. & $\begin{array}{l}\text { Defect } \\
\text { Rate } \\
(\%)\end{array}$ & $\begin{array}{l}\text { Quality } \\
\text { Standard }\end{array}$ & $\begin{array}{l}\text { Delivery } \\
\text { Time } \\
\text { (Days) }\end{array}$ & $\begin{array}{l}\text { Delivery Time } \\
\text { Standard }\end{array}$ \\
\hline 1 & $5 \%$ & Acceptable & -2 & Acceptable \\
\hline 2 & $3 \%$ & Acceptable & -2 & Acceptable \\
\hline 3 & $2 \%$ & Acceptable & -1 & Fine \\
\hline 4 & $0 \%$ & Fine & -2 & Acceptable \\
\hline \hline
\end{tabular}

The center of area method is applied for defuzzication to generate a discrete value from the fuzzy set. The crisp number for the next order quantity is 0.225 after the calculation (Fig. 3). It indicates that the toy company should decrease by 0.225 of the average quantity from the past records from Mayon Plastic Supply Co for the next order. The calculation is shown in the following equation:

Next Order Quantity = Quantity + (Average Quantity * $(-0.225))=20,000+(10,000 *(-0.225))=17,750$ units

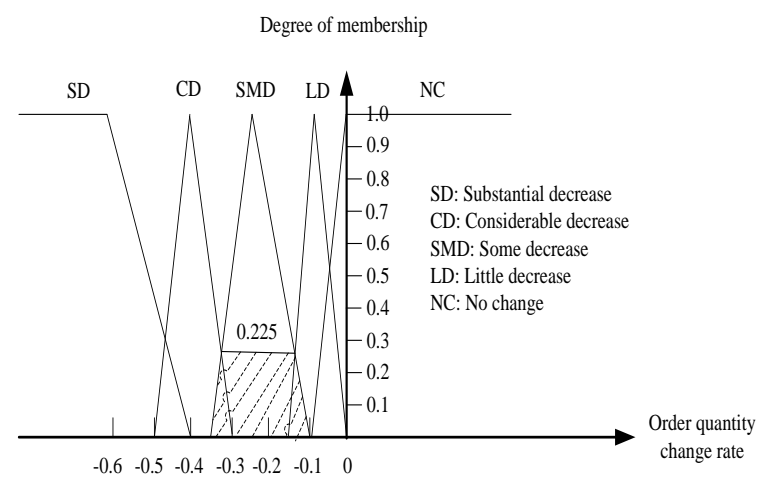

Fig. 3. Fuzzy pattern of order quantity change rate.
As shown in Fig. 3, the fuzzy logic approach suggests that the toy manufacturing company would decrease the purchasing order from Mayon Plastic Supply for the next order by 2250 units. In order to complete the order, the toy company will need to choose another company to order the rest of the 2250 .

\section{CONCLUSIONS}

It should be noted that the research work described in this paper has been assessed and proved in industry setting and relevant materials and knowledge have been disseminated in various occasions. However, further research is to extend the developed methodology to be incorporated in the optimization of supply chain trans-shipment operations where the stochastic lead times and uncertain customer demands are the areas that need to be explored. Funding has also been secured for further research along this line of study and the future work will include the enhancement and further development of this approach to cope with food supply chain where the condition of transportation particularly through the use of temperature-controlled containers is a vital consideration that needs to be addressed.

\section{REFERENCES}

[1] J. Magretta, "Fast, global, and entrepreneurial: Supply chain management, hong kong style," Harvard Business Review, vol. 76, no. 5, pp. 102-103, Sep.-Oct. 1998.

[2] D. Waters, Global Logistics and Distribution Planning, $3^{\text {rd }}$ ed., Kogan Page, 1999.

[3] D. N. Burt, N. David, and D. W. Dobler, Purchasing and Supply Management Text and Cases, $6^{\text {th }}$ ed., McGraw Hill Companies, Inc., 1996.

[4] R. E. Spekman, J. W. Kamauff, and N. Myhr, "An empirical investigation into supply chain management a perspective partnerships," International Journal of Physical Distribution and Logistics Management, vol. 28, no. 8, pp. 630-650, Oct. 1998.

[5] A. Beesley, "Time compression in supply chain," Industrial Management and Data Systms, vol. 96, no. 2, pp. 12-17, Feb. 1996.

[6] R. Halhead, "Breaking down the barriers to free information exchange," Logistics Information Management, vol. 8, no. 1, pp. 34-37, Jan. 1995.

[7] A. Tiwana, The Knowledge Management Toolkit, Prentice Hall, 2000.

[8] B. Andries and L. Gelders, "Time-based manufacturing logistics," Logistics Information Management, vol. 8, no. 3, pp. 30-36, May 1995.

[9] M. Zairi, Best Practice: Process Innovation Managemen, Butterworth-Heinemann, 1999.

[10] R. Nisel, "Analysis of consumer characteristics which influence the determinants of buying decisions by the logistic regression model," Logistic Information Management, vol. 14, no. 3, pp. 223-228, May 2001.

[11] M. Mourits and J. Evers, "Distribution network design: an integrated planning support framework," Logistics Information Management, vol. 9, no. 1, pp. 45-54, Jan. 1996.

[12] R. H. Ballou, Business Logistics Management: Planning, Organizing, and Controlling the Supply Chain, $4^{\text {th }}$ ed., Prentice Hall, London, 1999.

[13] D. J. Good and R. J. Schultz, Strategic Organization, and Managerial Impacts of Business Technologies, Quorum Books, London, 2000.

[14] V. Dhar and R. Stein, Seven Methods for Transforming Corporate Data into Business Intelligence, Prentice Hall, Inc., 1997.

[15] L. A. Zadeh, "Fuzzy sets," Information and Control, vol. 8, no. 3, pp. 338-383, Jun 1965.

[16] D. Driankov, H. Hellendoorn, and M. Reinfrank, An Introduction to Fuzzy Control, Springer, Prentice Hall, Inc., 1996.

[17] D. Dubois and H. Parade, "Mean value of a fuzzy number," Fuzzy Sets and Systems, vol. 24, no. 3, pp. 279-300, Dec. 1987.

[18] S. K. Tso, H. Lau, J. Ho, and W. J. Zhang, "A framework for developing agent-based collaborative service support system in a manufacturing information network," Engineering Applications of Artificial Intelligence, vol. 12, no. 1, pp. 43-57, Feb. 1999.

[19] W. B. Lee and H. Lau, "Multi-agent modeling of dispersed manufacturing network," Expert System with Applications, vol. 16, no. 3, pp. 297-306, Apr. 1999. 
[20] H. Lau and W. B. Lee, "On a responsive supply chain information system," International Journal of Physical Distribution and Logistics Management, vol. 31, no. 7/8, pp. 598-610, Oct. 2000.

[21] H. Lau, K. S. Chin, K. F. Pun, and A. Ning, "Decision Supporting functionality in a virtual enterprise network," Expert Systems with Applications, vol. 19, no. 4, pp. 261-270, Nov. 2000.

[22] S. Eilon, C. D. W. Gandy, and N. Christofides, Distribution Management: Mathematical Modelling and Practical Analysis, Charles Griffin and Company Ltd, London, 1971.

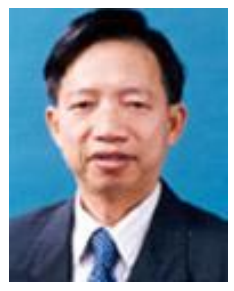

Henry Lau is currently a senior lecturer of the Schoo of Management at The University of Western Sydney, involving in research and teaching activities. He received his Masters degree at Aston University in Birmingham in 1981 and his Doctorate at the University of Adelaide in 1995. His current research areas cover logistics and supply chain management, operations research, engineering management and artificial intelligence systems. He has published more than 200 refereed journal papers, 10 book chapters, 1 textbook and attracted a total of HKD 20 million (about AUD 3 million) in research grants. In addition, he has, in total, been granted 4 patents and won 3 International awards for achievements in innovation. Over the years, he has been successful in publishing papers in a number of prestigious journals including Industrial Management and Data Systems, Production Planning and Control, Supply Chain Management, Management Reviews, Computers in Industry, Technology Management, Engineering Design, Production Research, Production Economics, IEEE Transactions on Systems, Man and Cybernetics Part A- Systems and Humans, IEEE Transactions on Industrial
Informatics and IEEE Transactions on Automation Science \& Engineering as well as IEEE Transactions on Evolutionary Computation.

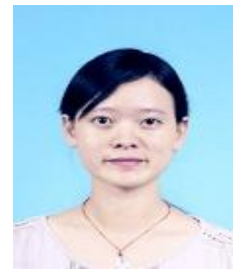

Li Zhao is currently a research assistant at School of Business, University of Western Sydney, Australia. She received her Bachelor degree of Management at the Xi'an Jiaotong University in Xi' an China in 2005, and $\mathrm{PhD}$ in supply chain risk studies at the Xi'an Jiaotong University in 2013. Her current research interests include quantitative research in supply chain and operations management, especially in the area of supply chain risk management. She has published papers in top journals like Supply Chain Management: An International Journal.

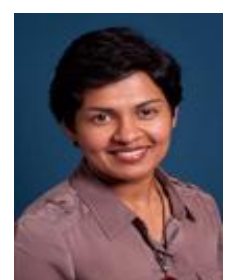

Dilupa Nakandala is a postdoctoral research fellow at the Centre for Industry and Innovation Studies Research Group, University of Western Sydney, Australia. She obtained her BSc in Electrical and Electronics Engineering (Grade 1) at the University of Peradeniya in 1998, MBA at the University of Moratuwa in 2004 and Ph.D. in innovation studies at the University of Western Sydney in 2010. Dilupa is a certified project management professional of the PMI,

USA. She has over eight years of industry experience in project and business management. Her research interests are in innovation, innovation systems, decision support systems, firm learning and development and renewable energy technologies. 